\title{
FATAL FAMILIAL INSOMNIA, A PRION DISEASE WITH A MUTATION AT CODON 178 OF THE PRION PROTEIN GENE
}

\author{
Rossella Medori, M.D., Hans-Jurgen Tritschler, Ph.D., Andréa LeBlanc, Ph.D., Federico \\ Villare, M.D., Valeria Manetto, M.D., Hsiao Ying Chen, M.Sc., Run Xue, M.D., Suzanne Leal, \\ M.S., Pasquale Montagna, M.D., Pietro Cortelli, M.D., Paolo Tinuper, M.D., Patrizia Avoni, \\ M.D., Mirella Mochi, M.D., Agostino Baruzzi, M.D., Jean Jaques Hauw, M.D., Jurg Ott, Ph.D., \\ Elio Lugaresi, M.D., Lucila Autilio-Gambetti, Ph.D., and Pierluigi Gambetti, M.D. \\ From the Division of Neuropathology, Case Western Reserve University, Cleveland (R.M., H.-J.T., \\ A.L., F.V., V.M., H.Y.C., R.X., L.A.-G., P.G.); the Department of Psychiatry, Columbia University, \\ NewYork (S.L., J.O.); the Neurological Institute, Bologna, Italy (P.M., P.C., P.T., P.A., M.M., A.B., \\ E.L.);and Clinique Neurologique and Laboratoire de Neuropathologie R.Escourolle, Hopital de la \\ Salpetriere, Paris (J.J.H.).
}

\section{Abstract}

Background.-We previously described two members of a family affected by an apparently genetically determined fatal disease characterized clinically by progressive insomnia, dysautonomia, and motor signs and characterized pathologically by severe atrophy of the anterior ventral and mediodorsal thalamic nuclei. Five other family members who died of this disease, which we termed "fatal familial insomnia," had broader neuropatho-logic changes suggesting that fatal familial insomnia could be a prion disease.

Methods.-We used antibodies to prion protein (PrP) to perform dot and Western blot analyses, with and without proteinase $\mathrm{K}$, on brain tissue obtained at autopsy from two patients with fatal familial insomnia, three patients with sporadic Creutzfeldt-Jakob disease, and six control subjects. The coding region of the PrP gene was amplified and sequenced in the samples from the two patients with fatal familial insomnia. Restriction-enzyme analysis was carried out with amplified PrP DNA from 33 members of the kindred.

Results.-Protease-resistant PrP was found in both patients with fatal familial insomnia, but the size and number of protease-resistant fragments differed from those in Creutzfeldt-Jakob disease. In the family with fatal familial insomnia, all 4 affected members and 11 of the 29 unaffected members had a point mutation in PrP codon 178 that results in the substitution of asparagine for

Reproduced with permission of copyright owner. Further reproduction prohibited without permission.

Address reprint requests to Dr. P.Gambetti at the Division of Neuropathology, Institute of Pathology, Case Western Reserve University, 2085 Adelbert Rd., Cleveland, OH 44106.

Note added in proof: Since this study was submitted, four additional kindreds with the same mutation as that of fatal familial insomnia havebeenreported. 10

We are indebted to Stanley Prusiner and Dan Serban for their generous supply of antibodies and invaluable advice, to Barbara Schaezle and Jennifer Secki for technical help, to Sandra Bowen for assistance in the preparation of the manuscript, and to the members of the kindred studied for their thoughtful and generous cooperation. 
aspartic acid and elimination of the Tth 11 I restriction site. Linkage analysis showed a close relation between the point mutation and the disease (maximal lod score, 3.4 when $\theta$ was zero).

Conclusions.-Fatal familial insomnia is a prion disease with a mutation in codon 178 of the PrP gene, but the disease phenotype seems to differ from that of previously described kindreds with the same point mutation.

IN 1986 we reported two cases of a rapidly progressive familial disease characterized clinically by untreatable insomnia, dysautonomia, and motor and pathologically by selective atrophy of the anterior ventral and mediodorsal thalamic nuclei ${ }^{1}$ (the thalamic nuclei as described by Hirai and Jones ${ }^{2}$ ). We named this disease fatal familial insomnia. ${ }^{1}$

Subsequently, clinical and pathological examinations were carried out in 5 other affected members of this kindred, ${ }^{3}$ which currently includes a total of 29 affected members from five generations and shows a pattern of inheritance consistent with autosomal-dominant transmission. The additional patients had more complex clinical and pathological features i.e., untreatable, progressive insomnia with impairment of the autonomic, endocrine, and motor systems. ${ }^{3}$ The sleep disorder is characterized by a marked reduction or loss of the slow-wave and rapid-eye-movement phases. In the more advanced stages these patients have complex hallucinations, followed in the terminal stages by stupor and coma. The dysautonomia includes hyperhidrosis, hyperthermia, tachycardia, and hypertension.

Corticotropin secretion is decreased and cortisol secretion is increased, with loss of circadian rhythm in the secretion of growth hormone, prolactin, and melatonin. Ataxia, dysarthria, myoclonus, and pyramidal signs are also invariably present. Memory and attention deficits are minimal in the early stages but progress with time, whereas many complex intellectual functions remain relatively well preserved. The mean age at onset of the disease is 49 years; the mean duration is 13 months.

Although histopathologically atrophy of the anterior ventral and mediodorsal nuclei of the thalamus remained the most prominent change, various degrees of atrophy and reactive astrogliosis were found in other thalamic nuclei, the cerebral and cerebellar cortexes, and the olives. Spongiosis of the cerebral cortex was observed in one member. The clinical and pathological findings in these new cases raised the question of whether fatal familial insomnia belongs to a group now identified as prion diseases, which includes genetically determined and sporadic forms of human neurodegenerative disorders such as CreutzfeldtJakob disease and Gerstmann-Straussler-Scheinker syndrome. ${ }^{4}$ They are transmissible and are characterized by the presence of an altered isoform of a protein that becomes resistant to treatment with proteases, called pro tease-resistant or prion protein $(\operatorname{PrP}) .{ }^{4}$

We undertook further studies of fatal familial insomnia to search for the presence of a protease-resist ant isoform of the PrP, a distinctive feature of prion diseases, and for a mutation in the PrP gene linked to the disease. 


\section{Methods}

\section{Pedigree and Additional Clinical Data}

The pedigree included 288 members of six generations, on which records had been kept since the early 19 thcentury $^{3}$ (Fig. 1). The entire kindred has always lived in the northern part of Italy, with the exception of Subject IV-37, who emigrated to France with her immediate family. Of the 29 members who may have been affected by the disease, 14 were recorded as possibly affected on the basis of nonmedical records, 8 were considered probably affected on the basis of medical records, and 7 were proved to be affected on the basis of histopathological examination. In the 14 possibly affected members the age at on set and the duration of the disease were not known;their mean age at death was 45 years (range, 13 to 65$)$. In the eight members who were probably affected, the mean age at onset was 44 years(range, 20 to 56); the mean duration of disease in seven (Subject IV-16 is stillliving) was 15 months (range, 6 to 42). In the seven members with histopathologically proved disease, the mean age at on set was 49 years (range, 35 to 61) and the mean duration 13 months (range, 7 to 25). We examined four patients clinically, in two of whom we confirmed the insomnia by 24-hour continuous poly-graphic recording.

In the early stages of the disorder, electroencephalography showed bitemporal slow waves, which later became generalized and slower. Periodic spike activity was observed only in Subjects V-58 and IV-16. The kindred member with focal areas of spongiosis in the cerebral cortex was Subject V-58.

\section{Tissue Samples}

Brain tissue, frozen at the time of autopsy, was obtained from two patients with fatal familial insomnia(Subjects IV-37 and V-58), three patients with histologically confirmed CreutzfeldtJakob disease, and six middle-aged subjects without neurologic or neuro-pathological abnormalities who served as controls. Blood samples were collected from 33 members of the kindred with fatal familial insomnia, including 1 member who was probably affected and 3 who were proved to be affected, and from 20 unrelated Italian subjects.

\section{Immunochemical Evaluation for PrP}

Antiserum R073 to hamster PrP and monoclonal antibody 5C10 (generously provided by S.Prusiner) were used at dilutions of 1:1000 and 1:10, respectively. ${ }^{5}$

Dot Blot Procedures-Samples of tissue from the cerebral cortexes of the frontal, temporal, parietal, and occipital lobes, the neostriatum, the thalamus, and the cerebellum were homogenized in 9 volumes of lysis buffer ( $100 \mathrm{mmol}$ of sodium chloride per liter, 10 mmol of EDTA per liter, 0.5 percent NP40 [Nonidet P-40, a nonionic detergent], 0.5 percent sodium deoxycholate, and $10 \mathrm{mmol}$ of TRIS per liter;pH 7.4). The homogenate was centrifuged at $500 \times \mathrm{g}$ for five minutes. Two hundred micro liters of the supernatant was then centrifuged (Airfuge, Beckman Instruments, Fullerton,Calif.)at 100,000× $\mathrm{g}$ for one hour. The pellet was suspended in 40 of lysis buffer and used in dot blot analysis as described by Serban et al. ${ }^{5}$ 
Western Blot Procedures-Tissues from the neostriatum, the thalamus, and the parietal and temporal cortexes (the tissues with the most positive results on dot blot testing of samples from patients with fatal familial insomnia) were homogenized as described above. Each homogenate was mixed with an equal volume of electrophoresis-sample buffer( 0.125 mol of TRIS per liter and 4 percent sodium dodecyl sulfate; $\mathrm{pH}$ 6.8) and incubated for one hour at $37^{\circ} \mathrm{C}$ with or without the addition of proteinase $\mathrm{K}(100 \mu \mathrm{g}$ per milliliter). The reaction was stopped by adding phenylmethylsulfonyl fluoride (final concentration, $1 \mathrm{mmol}$ per liter). The samples were resolved in 12 percent acrylamide gels and transferred to Immobilon $\mathrm{P}$ (polyvinylidine difluoride membrane; Millipore, Bedford, Mass.). Membranes were blocked in 5 percent nonfat milk and incubated with antiserum R073or monoclonal antibody $5 \mathrm{C} 10$ followed by an alkaline phosphatase-conjugated second antibody. The reaction was visualized with 5-bromo-4-chloro-3-indolyl-phosphate and nitroblue tetrazolium as substrates.

\section{Analyses of the PrP Gene}

Genomic DNA was extracted from peripheral blood or frozen brain tissue as described else where. ${ }^{6}$ The primers used for amplification were essentially those previously described, with slight modification of the downstream primer(GTACTGAGGATCCTCCT-

CATCCCACTATCAGGAAGA). ${ }^{7}$ Amplification was carried out for 30 cycles with an automated Perkin-Elmer thermal cycler(Ce-tus Instruments, Norwalk, Conn.);each cycle consisted of denaturationat $94^{\circ} \mathrm{C}$, annealing at $65^{\circ} \mathrm{C}$, and extension at $72^{\circ} \mathrm{C}$, with each step lasting one minute. Asymmetric amplification of the PrP coding region in samples from Subject IV-16 was performed with $30 \mathrm{pmol}$ of the excess primer and $0.3 \mathrm{pmol}$ of the limited primer, in a 100- $\mu$ l reaction volume. The single-stranded product was purified and concentrated by centrifugation (Centricon 100, Amicon,W.R. Grace, Beverly,Mass.)and sequenced with 0.1 pmol of the limited primer and a commercial kit(T7 Sequencing Kit,Pharmacia,Pis-cataway,N.J.)according to the manufacturer's instructions. Fragments of the amplified PrP coding region in the samples from Subjects IV-37 and V-58 were subcloned in order to sequence each allele of the PrP gene. The amplified 800-bp PrP double-stranded DNA was cleaved with the restriction enzymes HaeIII and DdeI. The two largest fragments generated (nucleotides 554 to 726 and nucleotides 213 to 432$)^{8}$ were ligated at the blunt ends to the Smalsite of pBluescript II KS ${ }^{-}$(Stratagene,La Jolla,Calif.)and sequenced with Sequenase Version 2.0(United States Biochemical, Cleveland). The amplified DNA was digested with Tth 111 I (Boeh-ringer-Mannheim, Mannheim, Germany) for two hours, and the fragments were separated through a 1 percent agarose gel and visualized with ethidium bromide.

\section{Linkage Analysis}

Linkage analysis(with the MLINK computer program ${ }^{9}$ )was carried out to test for linkage between the phenotype for fatal familial insomnia and the point mutationin codon 178 of the PrP gene; in this mutation, asparagine is substituted for aspartic acid. A total of 63 members of the kindred were included in the analysis: 15 members who carried the mutation(4 members who were known to be affected according to his topathological examination or who were considered to be probably affected and 11 who were asymptomatic), 18 members who had no mutation and were asymptomatic( 3 of whom had married into the kindred), and 
30 members for whom information on disease markers was not available (6 members were histopathologically confirmed to be affected or were considered to be probably affected, 9 were considered to be possibly affected, 1 was asymptomatic, and 14 had married into the kindred).

Only members who were known to be affected according to histopathological examination or who were considered to be probably affected were included in the analysis as affected members; there was a total of 15 . Members who had married into the kindred were considered to be unaffected. All other family members were considered to have an unknown status, there by allowing for incomplete penetrance of the disease. To estimate the frequency of the point mutation (GAC $\rightarrow$ AAC in the PrP codon 178), a sample of 103 unrelated subjects of European ancestry were evaluated(20 subjects from this study and 83 from another study ${ }^{10}$ );none were found to have the mutation(no mutation among the 206 alleles).

\section{Results}

\section{PrP ImmunochemicalStudies}

Dot blot immunoassays revealed protease-resistant $\operatorname{PrP}$ in both patients with fatal familial insomnia who were studied, Subjects V-58 and IV-37 (Fig. 2). The immunoreaction was stronger and was present in more brain regions in Subject V-58 than in Subject IV-37. Immunoreaction was very intense in the patients with Creutzfeldt-Jakob disease but was absent in the controls. These findings indicate that a protease-resistant isoform of PrP was present in the two patients with fatal familial insomnia and in larger amounts and with a wider distribution in Subject V-58.

Western blot analysis of undigested samples showed three or four bands between 29 and 35 $\mathrm{kd}$ in all subjects examined, in agreement with the reported size of PrP. ${ }^{11,12}$ The size of the proteinase $\mathrm{K}$-resistant fragments from the patients with fatal familial insomnia differed from the size of those from the patients with Creutzfeldt-Jakob disease. Although all three patients with Creutzfeldt-Jakob disease had three reactive bands of approximately 29, 25, and $21 \mathrm{kd}$, comparable in size to bands recently reported, ${ }^{12}$ both patients with fatal familial insomnia had two bands of 29 and $27 \mathrm{kd}$ (Fig. 3). The finding that the proteinase K-resistant fragments in fa tal familial insomnia and sporadic Creutzfeldt-Jakob disease differ in number and size suggests that they derive from different abnormal isoforms of PrP.

\section{Analysis of the PrP Gene}

DNA sequencing of samples from three affected family members (Subjects IV-16, IV-37, and V-58) demonstrated heterozygosity of the GAC $\rightarrow$ AAC mutation in codon 178 of the PrP coding region that results in the substitution of asparagine for aspartic acid (Fig. 4). Since this mutation abolishes a normal Tth 111 I restriction site, the amplified coding region of the PrP gene was digested with Tth 111 I in samples from 30 additional members of the kindred with fatal familial insomnia, including 1 member with histopathologically confirmed disease (Subject IV-21); this member also carried the mutation. Thus, the mutation was present in all 4 affected members tested (Fig. 5) and also in 11 unaffected members, 3 of whom were between 61 and 63 years of age. No mutation was found in 18 
unaffected members, 8 of whom were between 60 and 78 years of age, or in the 20 unrelated Italian subjects tested. The presence of the mutation in several un affected members whose ages were well within the range of ages at the onset of the disease indicates that the penetrance of fatal familial insomnia is incomplete.

\section{Linkage Analysis}

A strong linkage was found between fatal familial insomnia and the $\mathrm{GAC} \rightarrow \mathrm{AAC}$ point mutation in codon 178 of the PrP gene, with a maximal lod score of 3.4 when $\theta$ was zero (Table 1).

\section{Discussion}

The present study demonstrates that fatal familial insomnia, a disease characterized by untreatable insomnia, dysautonomia, motor signs, and selective atrophy of thalamic nuclei, is linked to a mutation in codon 178 of the PrP gene. The presence of a disease-linked mutation in the PrP gene and the finding of the protease-resistant PrP isoform in brain tissues indicate that fatal familial insomnia is a genetically determined prion disease.

The discovery of a mutation in the PrP gene in patients with the disorder, which does not conform easily to any of the major known PrP diseases, raises at least two issues. First, the finding that fatal familial insomnia is a prion disease widens the spectrum of these disorders and supports the contention that they are more common than previously suspected. ${ }^{13}$ Second, as a disease linked to a mutation in codon 178 of the PrP gene, fatal familial insomnia underscores the problems raised by the lack of consistent correlations between genetic defect and disease phenotype.

The mutations associated with the familial forms of PrP diseases include insertions of six-, seven-, or nineoctapeptide repeats and point mutations at codons 102, 200, 117, 198, and 178. ${ }^{4,14}$ Currently, these mutations can be classified in four groups according to the disease phenotype. The insertions, which form the first group, express heterogeneous clinical and pathological phenotypes. ${ }^{14-16}$ Among patients with the clinical phenotype of the sixoctapeptide insertion, the age at onset and the duration of disease vary greatly and the neuropathological features within the same kindred range from widespread spongiosis to minimal changes without spongiosis or gliosis. ${ }^{14-16}$ Likewise, patients with the sevenoctapeptide insertion also have heterogeneous clinical and pathologic features. ${ }^{14}$ In the second group are the mutations at co-dons 102, 117, and 198. They appear to express phenotypes that are consistent with various forms of Gerstmann-Straussler-Scheinker syndrome. ${ }^{4,17}$ The mutation at codon 102 segregates with the ataxic form;the telencephalic form is linked to the mutation at codon 117 , and the variant with neurofibrillary tangles correlates with the mutatitfh at codon $198 .{ }^{17}$ A phenotype fairly typical of CreutzfeldtJakob disease, produced by a mutation at codon 200 , constitutes the third group. ${ }^{14}$ The fourth group includes the mutation at codon 178. This mutation, which we have identiflid in patients with fatal familial insomnia, has been described in four unrelated families, ${ }^{18,19}$ identified here according to the nomenclature of Masters et al. ${ }^{20}$ as kindred OS (Finnish), 21,22 kindred MD (American, of Dutch ancestry), ${ }^{20}$ kindred ST (American, of HungarianRomanian ancestry), ${ }^{23,24}$ and kindred AB (French). ${ }^{20,25}$ Detailed clinical and pathological 
data have been published only for kindreds ST, OS, and $\mathrm{AB}^{21-25}$; they show that the disease is remarkably similar in these three kindreds. ${ }^{21}$ Similar clinical and pathologic changes are apparently also present in kindred MD ${ }^{18-20}$ (and Ghodosh HL:personal communication).

Comparison of the clinical and histopathologic features of kindreds ST, OS, and AB with those of the kindred we have described (Table 2) reveals similarities in the range of ages at onset and the duration of disease, the presence of motor signs, and the absence of periodic sharp-wave complexes on the electroencephalogram. However, memory impairment, which was the presenting and dominant sign in kindreds ST, OS, and AB, was mild and occurred relatively late in the kindred with fatal familial insomnia we studied. ${ }^{3}$ Sleep and dysautonomic disturbances, which are distinctive features of this disorder, have been reported in only a single member of the other three kindreds. Cerebral cortical spongiosis, widespread in kindreds ST, OS, and AB, was absent in all but one patient with fatal familial insomnia in the kindred we studied. Conversely, severe atrophy of the anterior ventral and mediodorsal thalamic nuclei, the hallmark of fatal familial insomnia, as well as cerebellar and olivary involvement, has not been observed in the other kindreds.

We recently examined a second, unrelated kindred with clinical and pathologic features identical to those of the original cohort with fatal familial insomnia, and found the same mutation at codon 178 (unpublished data). Therefore, this mutation seems to be expressed in two different disease phenotypes: one phenotype in kindreds OS, ST, AB, and possibly MD, and the other in the two kindreds with fatal familial insomnia.

Consistent differences in clinical and pathological phenotypes among kindreds with the same genetic defect cannot be easily explained at present. A recent study has shown that a clinical feature such as the age at the time of death correlated with the presence of polymorphism at codon 129 of the PrP gene. ${ }^{15}$ Differences in the age at onset of the disease have also been attributed to genomic imprinting, which may differentially affect the level of expression of parental genes. ${ }^{26}$ Polymorphism in the PrP gene or in genes modulating PrP expression, as well as changes in the regulation of gene expression, may therefore explain the differences between the phenotypes of the kindreds with fatal familial insomnia and those of the other kindreds, despite the presence of the same mutation in all of them. It is also possible that the site and type of mutation in the primary sequence of PrP influences the onset and duration of disease but affects less, or not at all, the type and distribution of the lesions, which may be modulated by other genetic events. However, before a difference in disease phenotype among kindreds with the codon-178 mutation in the PrP gene can definitely be accepted, more patients among kindreds other than those with fatal familial insomnia must be carefully examined. Sleep and autonomic and endocrine dys-functions must be specifically searched for in the other kindreds with this mutation, since such dysfunctions may be present in all patients with this mutation and perhaps also in those with other mutations of the PrP gene.

The amount of protease-resistant PrP on dot blots and the number of brain regions from which the protease-resistant PrP could be recovered were consistently higher in Subject V-58 than in Subject IV-37. Moreover, no protease-resistant PrP was consistently detected in various brain regions of an affected member of the second, unrelated kindred with fatal 
familial insomnia due to the same PrP-gene mutation (unpublished data). Since the duration of the disease was 25 months in Subject V-58, 18 months in Subject IV-37, and 7 months in the member of the second kindred, the amount of protease-resistant PrP is likely to be related to the duration of the disease. Consistent with this hypothesis are reports that the presence of plaques containing large deposits of protease-resistant $\operatorname{PrP}$ is related to the duration of disease and that the formation and accumulation of protease-resistant PrP are a slow process. ${ }^{4,27}$

The remarkable difference between the size of the protease-resistant PrP fragments from the two patients with fatal familial insomnia and the size of those from the three patients with sporadic Creutzfeldt-Ja-kob disease suggests that the abnormal PrP isoforms present in these two disorders are also different. Whether this difference is related to the codon-178 mutation or to other factors remains to be elucidated.

\section{Acknowledgments}

Supported by a grant(NS-14509)from the National Institute of Neurological Disorders and Stroke, grants(ADRCAG-08012,AG-08992, and 1 R01 AG NS-08155)from the National Institute on Aging, a grant from the Britton Fund(to Dr. P.Gambetti), and a grant(HG-00008)from the National Center for Human Genome Research(to Dr. Ott).

\section{References}

1. Lugaresi E,Medori R,Montagna P, et al. Fatal familialin somnia and dysautonomia with selective degeneration of thalamic nuclei. N Engl J Med 1986;315:997-1003. [PubMed: 3762620]

2. Hirai T, Jones EG. A new parcellation of the human thalamus on the basis of histochemical staining. Brain Res Brain Res Rev 1989;14:1-34. [PubMed: 2720229]

3. Manetto V, Medori R, Cortelli P, et al. Fatal familialin somnia clinical and pathological study of five new cases. Neurology(in press).

4. Prusiner SB. Molecular biology of prion diseases. Science 1991;252:1515-22. [PubMed: 1675487]

5. Serban D, Taraboulos A, DeArmond SJ, Prusiner SB. Rapid detection of Creutzfeldt-Jakob disease and scrapie prion proteins. Neurology 1990;40: 110-7. [PubMed: 1967489]

6. Maniatis T, Fritsch EF, Sambrook J.Molecularcloning:a laboratory manual.Cold Spring Harbor,N.Y:Cold Spring Harbor Laboratory,1982.

7. Goldgaber D, Goldfarb LG, Brown P, et al. Mutations in familial Creutz-feldt-Jakob disease and Gerstmann-Straussler-Scheinker's syndrome. Exp Neurol 1989;106:204-6. [PubMed: 2572450]

8. Kretzschmar HA, Stowring LE, Westaway D, Stubblebine WH, Prusiner SB, Dearmond SJ. Molecular cloning of a human prion protein cDNA. DNA 1986;5:315-24. [PubMed: 3755672]

9. Lathrop GM, Lalouel JM, Julier C, Ott J. Multilocus linkage analysis in humans:detection of linkage and estimation of recombination. Am J Hum Genet 1985;37:482-98. [PubMed: 3859205]

10. Goldfarb LG, Brown P, Haltia M, et al. Creutzfeldt-Jakob disease cosegre-grates with codon $178^{\text {Asn }}$ PRNP mutation in families of European origin. Ann Neurol 1992;31:274-81. [PubMed: 1353341]

11. Bolton DC, McKinley MP, Prusiner SB. Identification of a protein that purifies with the scrapie prion. Science 1982;218:1309-11. [PubMed: 6815801]

12. Kitamoto T, Muramoto T, Hilbich C, Beyreuther K, Tateishi J. N-terminal sequence of prion protein is also integrated into kuru plaques in patients with Gertsmann-Straussler syndrome. Brain Res 1991;545:319-21. [PubMed: 1677605]

13. Owen F, Poulter M, Collinge J, et al. Insertions in the prion protein gene in atypical dementias. Exp Neurol 1991;112:240-2. [PubMed: 1674696]

14. Brown P, Goldfarb LG, Gajdusek DC. The new biology of spongiform encephalopathy:infectious amyloidoses with a genetic twist. Lancet 1991;337:1019-22. [PubMed: 1673176] 
15. Baker HF, Poulter M, Crow TJ, et al. Aminoacid polymorphism in human prion protein and age at death in inherited prion disease. Lancet 1991;337:1286.

16. Owen F, Poulter M, Shah T, et al. An in-frame insertion in the prion protein gene in familial Creutzfeldt-Jakob disease. Brain Res Mol Brain Res 1990;7: 273-6. [PubMed: 2159587]

17. Hsiao KK, Cass C, Schellenberg GD, et al. A prion protein variant in a family with the telencephalic form of Gerstmann-Straussler-Scheinker syndrome. Neurology 1991;41:681-4. [PubMed: 1674116]

18. Goldfarb LG, Haltia M, Brown P, et al. New mutation in scrapie amyloid precursor gene(at codon 178)in Finnish Creutzfeldt-Jakob kindred. Lancet 1991;337:425.

19. Nieto A, Goldfarb LG, Brown P, et al. Codon 178 mutation in ethnically diverse Creutzfeldt-Jakob disease families. Lancet 1991;337:622-3.

20. Masters CL, Gajdusek DC, Gibbs CJ, Jr. The familial occurrence of Creutzfeldt-Jakob disease and Alzheimer's disease. Brain 1981;104:535-58. [PubMed: 7023604]

21. Haltia M, Kovanen J, Van Crevel H, Bots GT, Stefanko S. Familial Creutz-feldt-Jakob disease. J Neurol Sci 1979;42:381-9. [PubMed: 390100]

22. Kovanen J, Haltia M. Descriptive epidemiology of Creutzfeldt-Jakob disease in Finland. Acta Neurol Scand 1988;77:474-80. [PubMed: 3043996]

23. Friede RL, DeJong RN. Neuronal enzymatic failure in Creutzfeldt-Jakob disease. Arch Neurol 1964;10:181-95. [PubMed: 14088252]

24. May WW, Itabashi HH, DeJong RN, Arbor A. Creutzfeldt-Jakob disease. II.Clinical, pathologic, and genetic study of a family. Arch Neurol1968;19: 137-49. [PubMed: 5675300]

25. Guidon G. Formes familiales de la maladie de Creutzfeldt-Jakob:a propos d'une fratrie de deux. (These pour le Doctorat en Medecine(diplome d'Etat).Rennes,France:Universite de Rennes,1978.)

26. Wexler NS, Rose EA, Housman DE. Molecular approaches to hereditary diseases of the nervous system:Huntington's disease as a paradigm. Annu Rev Neurosci 1991;14:503-29. [PubMed: 1827708]

27. Kitamoto T, Tateishi J. Immunohistochemical confirmation of Creutzfeldt-Jakob disease with a long clinical course with amyloid plaque core antibodies. Am J Patho 11988;131:435-43. 


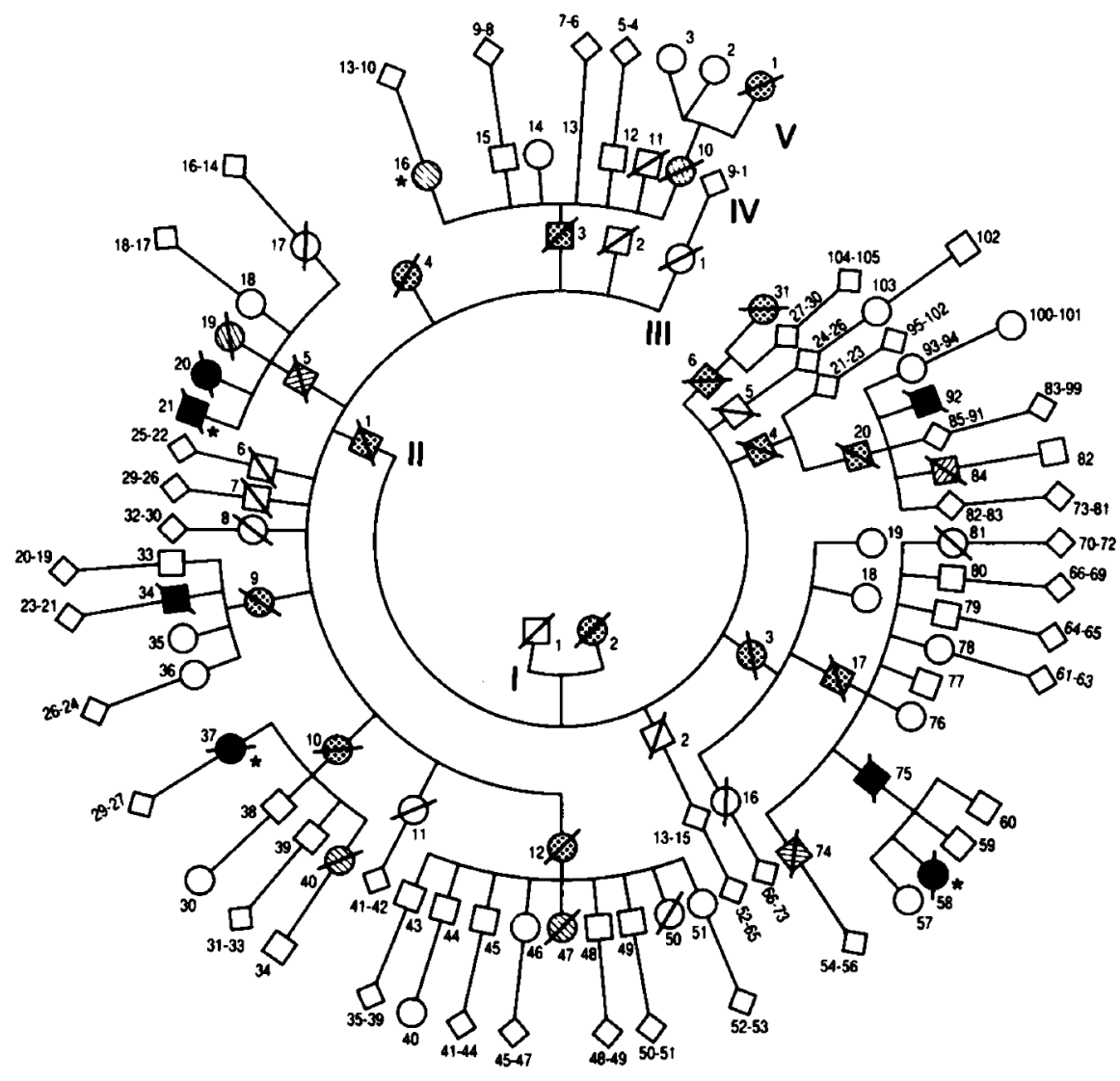

Figure 1. Pedigree of a Kindred with Fatal Familial Insomnia.

Squares denote male subjects, circles female subjects, diamonds subjects of either sex, and slashed symbols dead subjects. Stippled symbols denote subjects possibly affected according to nonmedical records; hatched symbols, subjects probably affected according to medical records; solid symbols, subjects proved to be affected, by histologic examination; and symbols with asterisks, subjects examined clinically in the present study. The sixth generation, which had no affected members, is not shown. 


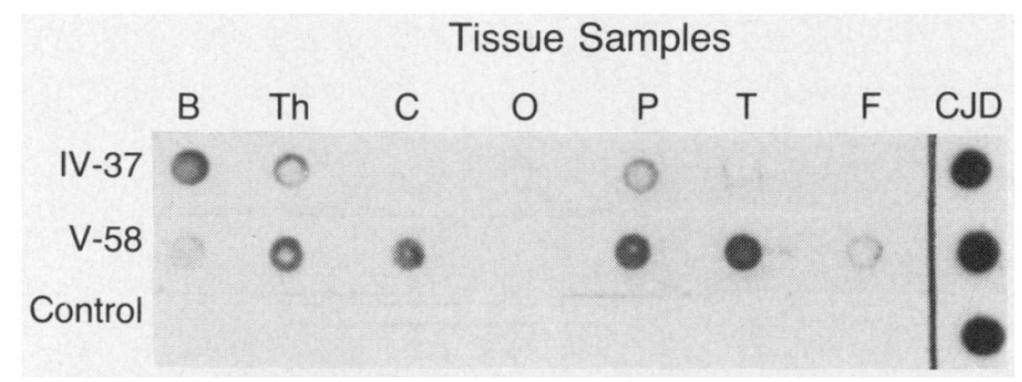

Figure 2. Dot Blots Demonstrating Protease-Resistant PrP in Two Subjects with Fatal Familial Insomnia.

Dots representing samples of brain tissue were treated with proteinase $\mathrm{K}$ and subjected to immunoreaction with antiserum R073.5 Tissue samples were obtained from the basal ganglia (B), thalamus (Th), and cerebellum (C) and from the occipital (O), parietal (P), temporal (T), and frontal (F) cortical areas of Subjects IV-37 and V-58 and a control; cerebral cortical tissue from a subject with sporadic Creutzfeldt-Jakob disease (CJD) was used as a positive control. The immunoreaction was stronger and was present in more brain regions in Subject V-58 than in Subject IV-37; it was very strong in the subject with Creutzfeldt-Jakob disease and absent in the control. 


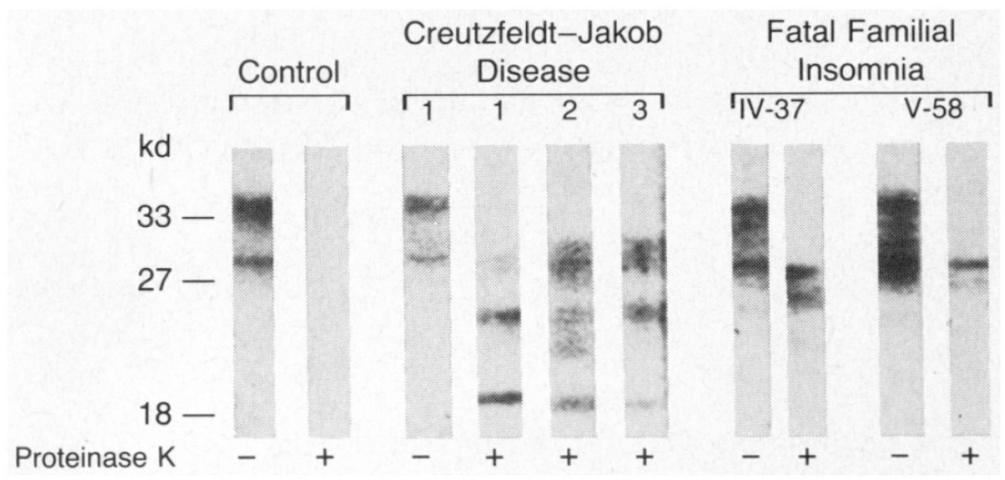

Figure 3. Western Blots Showing the Size of the PrP Fragments Generated by Treatment with Proteinase K.

The blots are those of a control, three subjects with sporadic Creutzfeldt-Jakob disease (1, 2, and 3), and two subjects with fatal familial insomnia (IV-37 and V-58). Molecular-weight markers are expressed in kilodaltons, at left. Plus signs and minus signs denote treatment with proteinase $\mathrm{K}$ and no treatment, respectively. The protease-resistant fragments from the subjects with fatal familial insomnia differ in size from those from the subjects with Creutzfeldt-Jakob disease. 


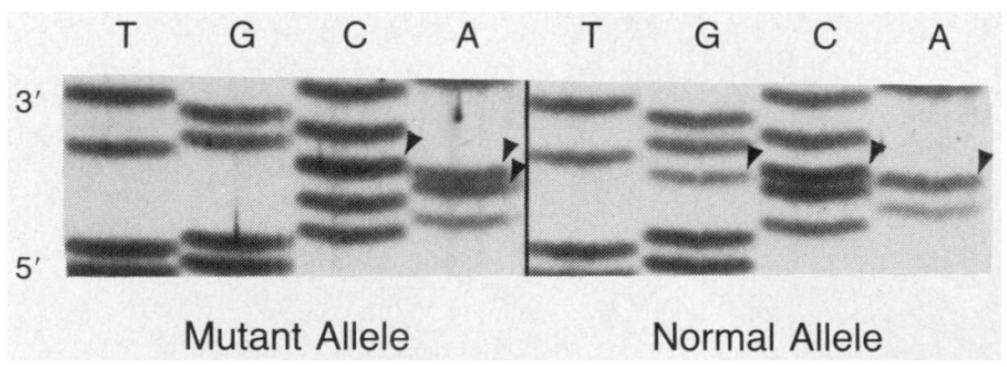

Figure 4. Autoradiograph of Sequencing Gel from Part of the PrP Coding Region in the Mutant and Normal Alleles of Subject V-58.

The three bands that identify the three base pairs of codon 178 in the two alleles are indicated by arrowheads. The GAC $\rightarrow$ AAC mutation that leads to the substitution of asparagine for aspartic acid can be detected by comparing codon 178 in the two alleles. The same findings were made in Subjects IV-16 and IV-37. The DNA bases are indicated at the top of the figure. 


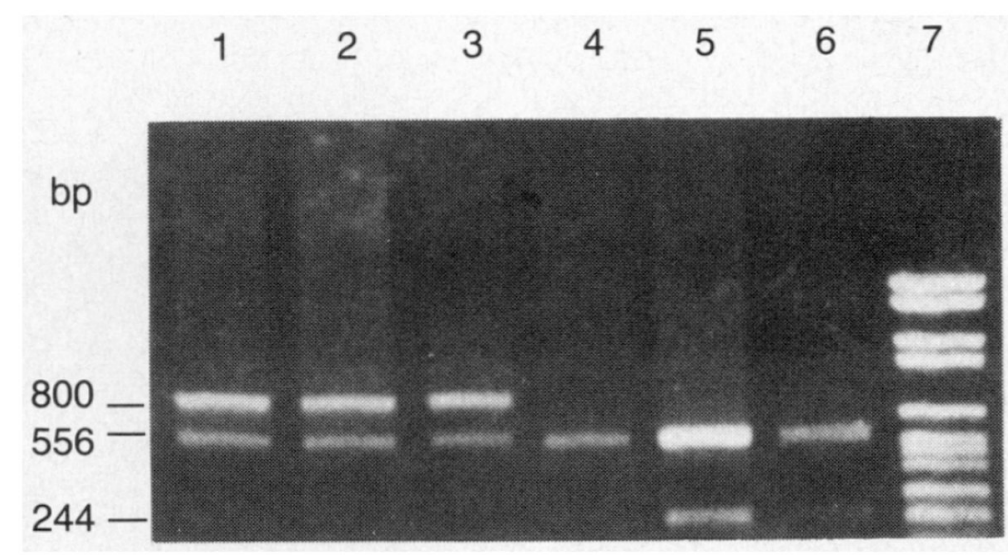

Figure 5. Tth 111 I Digestion of the 800-bp Amplified PrP Coding Region in Samples from Six Members of the Kindred with Fatal Familial Insomnia.

Three bands of 800,556 , and 244 bp are present in members carrying the GAO $\rightarrow$ AAC mutation, which abolishes the Tth 111 I restriction site in one of the two alleles (lanes 1, 2, and 3). Only two fragments of 556 and $244 \mathrm{bp}$ are present in members without the mutation (lanes 4, 5, and 6), since both alleles are completely digested (these members are not identified, to protect confidentiality). Lane 7 represents DNA markers - i.e., the products of Bg/l-digested and H/nfl-digested pBR322 DNA. 
Table 1.

Lod Scores for Linkage between Fatal Familial Insomnia and the Codon-178 PrP Mutation. ${ }^{*}$

\begin{tabular}{cccccc}
\hline \multirow{2}{*}{$\mathbf{c}$} & \multicolumn{5}{c}{ RECOMBINATION FRACTION } \\
& 0 & 0.05 & 0.10 & 0.15 & 0.20 \\
0.022 & 3.064 & 2.783 & 2.488 & 2.180 & 1.858 \\
0.014 & 3.185 & 2.901 & 2.602 & 2.290 & 1.963 \\
0.010 & 3.250 & 2.965 & 2.665 & 2.350 & 2.020 \\
0.001 & 3.416 & 3.127 & 2.823 & 2.503 & 2.167 \\
0.0001 & 3.434 & 3.145 & 2.840 & 2.520 & 2.184 \\
$10^{-7}$ & 3.436 & 3.147 & 2.842 & 2.522 & 2.185 \\
\hline
\end{tabular}

* The 95 percent confidence interval for the allele frequency, p, extends from 0 to 0.014 , and the 99 percent confidence interval from 0 to 0.022 . The frequency of the disease gene was assumed to be at most $q=0.00005$ (use of lower values of q did not change the results). 
Table 2.

Clinical and Histopathological Findings in Kindreds with the Codon-178 PrP Mutation.

\begin{tabular}{|c|c|c|c|c|c|c|}
\hline KINDRED* & NO. OF PATIENTS & $\begin{array}{c}\text { AGE AT } \\
\text { ONSET } \\
\text { (YR) }\end{array}$ & $\begin{array}{l}\text { DURATION } \\
\text { OF DISEASE } \\
\text { (MO) }\end{array}$ & CLINICAL SIGNS & $\mathbf{E E G}^{\dagger}$ & HISTOPATHOLOGY \\
\hline \multicolumn{7}{|c|}{ mean (range) } \\
\hline ST; Hungarian-Romanian ancestry ${ }^{23,24}$ & $4 t$ & $41(38-45)$ & $15(10-20)$ & $\begin{array}{l}\text { Presenting with } \\
\text { memory deficit, } \\
\text { "nervousness," } \\
\text { confusion, and } \\
\text { disorientation, then } \\
\text { tremors or } \\
\text { myoclonus, ataxia, } \\
\text { hyperreflexia, } \\
\text { speech difficulties, } \\
\text { mutism, vegetative } \\
\text { disturbances }\end{array}$ & - & $\begin{array}{l}\text { Widespread spongiosis of } \\
\text { cerebral cortex especially } \\
\text { hippocampus, and basal } \\
\text { ganglia; occasional mild } \\
\text { spongiosis and gliosis, but } \\
\text { no neuronal loss in the } \\
\text { anterior ventral and } \\
\text { mediodorsal thalamus; no } \\
\text { changes in cerebellum and } \\
\text { olives }\end{array}$ \\
\hline OS; Finnish ancestry ${ }^{20-22}$ & $6^{\mathcal{s}}$ & $50(46-53)$ & $21(11-36)$ & $\begin{array}{l}\text { Presenting with } \\
\text { memory deficit, } \\
\text { then ataxia, } \\
\text { disorientation, } \\
\text { speech difficulties } \\
\text { progressing to } \\
\text { mutism, tremors or } \\
\text { myoclonus, and } \\
\text { hyperreflexia }\end{array}$ & - & $\begin{array}{l}\text { Spongiosis of cerebral } \\
\text { cortex, as in kindred ST; } \\
\text { moderate spongiosis, } \\
\text { neuronal loss, and gliosis in } \\
\text { thalamus; no changes in } \\
\text { cerebellum and olives }\end{array}$ \\
\hline AB; French ancestry 25 & $2^{I I}$ & $47(46-48)$ & $\approx 12(10-14 ?)$ & $\begin{array}{l}\text { Presenting with } \\
\text { memory deficit } \\
\text { and tremor, then } \\
\text { ataxia, speech } \\
\text { impairment, } \\
\text { myoclonus, } \\
\text { hyperreflexia, and } \\
\text { global } \\
\text { deterioration of } \\
\text { mental functions }\end{array}$ & - & Cerebral cortical spongiosis \\
\hline \multirow[t]{3}{*}{ Present study; Italian ancestry ${ }^{3}$} & $7^{\prime \prime}$ & $49(35-61)$ & $13(7-25)$ & $\begin{array}{l}\text { Subject IV-21 } \\
\text { (onset at } 52 \text { yr): } \\
\text { presenting with } \\
\text { insomnia and } \\
\text { vegetative } \\
\text { disturbances, then } \\
\text { enacted dreams, } \\
\text { confusion, } \\
\text { dysarthria, mutism, } \\
\text { myoclonus, } \\
\text { hyperreflexia, } \\
\text { spasticity and } \\
\text { incontinence } \\
\text { (duration of } 9 \mathrm{mo} \text { ) }\end{array}$ & - & $\begin{array}{l}\text { Severe atrophy of anterior } \\
\text { ventral and mediodorsal } \\
\text { thalamic nuclei; various } \\
\text { degrees of gliosis of other } \\
\text { thalamic nuclei and } \\
\text { cerebral cortex; torpedo } \\
\text { formation in cerebellum; } \\
\text { various degrees of atrophy } \\
\text { of olives; mild cerebral } \\
\text { cortical spongiosis in } \\
\text { Subject V-58 only }\end{array}$ \\
\hline & & & & $\begin{array}{l}\text { Subject IV-37 } \\
\text { (onset at } 61 \mathrm{yr} \text { ): } \\
\text { presenting with } \\
\text { insomnia and } \\
\text { vegetative } \\
\text { disturbances, then } \\
\text { enacted dreams, } \\
\text { dysarthria, ataxia, } \\
\text { myoclonus, and } \\
\text { rigidity (duration } \\
\text { of } 18 \text { mo) }\end{array}$ & - & \\
\hline & & & & $\begin{array}{l}\text { Subject V-58 } \\
\text { (onset at } 35 \mathrm{yr} \text { ): } \\
\text { presenting with } \\
\text { ataxia, then } \\
\text { dysarthria, } \\
\text { insomnia, }\end{array}$ & + & \\
\hline
\end{tabular}




\begin{tabular}{|c|c|c|c|c|c|c|}
\hline KINDRED* & NO. OF PATIENTS & $\begin{array}{c}\text { AGE AT } \\
\text { ONSET } \\
\text { (YR) }\end{array}$ & $\begin{array}{l}\text { DURATION } \\
\text { OF DISEASE } \\
\text { (MO) }\end{array}$ & CLINICAL SIGNS & $\mathbf{E E G}^{\dagger}$ & HISTOPATHOLOGY \\
\hline \multicolumn{7}{|c|}{ mean (range) } \\
\hline & & & & $\begin{array}{l}\text { vegetative } \\
\text { disturbances, } \\
\text { mutism, enacted } \\
\text { dreams, confusion, } \\
\text { myoclonus, and } \\
\text { generalized } \\
\text { myoclonic seizures } \\
\text { (duration of } 25 \\
\text { mo) }\end{array}$ & & \\
\hline
\end{tabular}

* The first three kindreds are identified according to the nomenclature of Masters et al. ${ }^{20}$

${ }^{\dagger}$ A plus sign indicates the presence of periodic spike activity on electroencephalography (EEG), and a minus sign its absence.

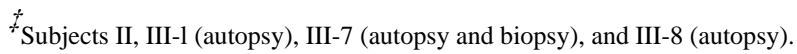

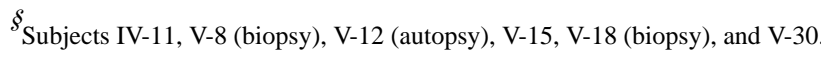

${ }^{q I}$ Subjects III-2 and I1I-3 (biopsy).

"Subjects IV-20 (autopsy), IV-21 (clinical examination and autopsy), IV-34 (autopsy), IV-37 (clinical examination and autopsy), IV-75 (autopsy), IV-92 (autopsy), and V-58 (clinical examination and autopsies). 